\title{
The role of caspase-8 in amyloid-induced beta cell death in human and mouse islets
}

\author{
Yoo Jin Park • Minna Woo • Timothy J. Kieffer • \\ Razqallah Hakem • Nooshin Safikhan • Fan Yang • \\ Ziliang Ao • Garth L. Warnock • Lucy Marzban
}

Received: 11 September 2013 / Accepted: 2 December 2013 / Published online: 19 January 2014

(C) Springer-Verlag Berlin Heidelberg 2014

\begin{abstract}
Aims/hypothesis Reduced beta cell mass due to increased beta cell apoptosis is a key defect in type 2 diabetes. Islet amyloid, formed by the aggregation of human islet amyloid polypeptide (hIAPP), contributes to beta cell death in type 2 diabetes and in islet grafts in patients with type 1 diabetes. In this study, we used human islets and $\mathrm{h} I A P P$-expressing mouse islets with beta cell Casp 8 deletion to (1) investigate the role of caspase- 8 in amyloid-induced beta cell apoptosis and (2) test whether caspase-8 inhibition protects beta cells from amyloid toxicity. Methods Human islet cells were cultured with hIAPP alone, or with caspase-8, Fas or amyloid inhibitors. Human islets and wild-type or $\mathrm{h} I A P P$-expressing mouse islets with or without
\end{abstract}

Electronic supplementary material The online version of this article (doi:10.1007/s00125-013-3152-1) contains peer-reviewed but unedited supplementary material, which is available to authorised users.

Y. J. Park $\cdot$ T. J. Kieffer $\cdot$ N. Safikhan $\cdot$ F. Yang $\cdot$ Z. Ao •

G. L. Warnock $\cdot$ L. Marzban $(\bowtie)$

Department of Surgery, Faculty of Medicine, University of British

Columbia, Jim Pattison Pavilion, Vancouver General Hospital,

910 W 10th Ave., Vancouver, BC, Canada V5Z 4E3

e-mail: lucy.marzban@ubc.ca

M. Woo

Toronto General Research Institute, Toronto, ON, Canada

M. Woo

Department of Medicine, Toronto General Hospital, University

Health Network, University of Toronto, Toronto, ON, Canada

\section{T. J. Kieffer}

Department of Cellular and Physiological Sciences, Faculty of Medicine, Life Sciences Institute, University of British Columbia, Vancouver, BC, Canada

R. Hakem

Department of Medical Biophysics, Ontario Cancer Institute,

University of Toronto, Toronto, ON, Canada caspase-8 expression (generated using a Cre/loxP system) were cultured to form amyloid. Caspase- 8 and -3 activation, Fas and FLICE inhibitory protein (FLIP) expression, islet beta cell and amyloid area, IL-1 $\beta$ levels, and the beta:alpha cell ratio were assessed.

Results hIAPP treatment induced activation of caspase- 8 and -3 in islet beta cells (via Fas upregulation), resulting in apoptosis, which was markedly reduced by blocking caspase-8, Fas or amyloid. Amyloid formation in cultured human and $\mathrm{h} I A P P$-expressing mouse islets induced caspase- 8 activation, which was associated with Fas upregulation and elevated islet IL-1 $\beta$ levels. hIAPP-expressing mouse islets with Casp 8 deletion had comparable amyloid, IL-1 $\beta$ and Fas levels with those expressing hIAPP and Casp 8 , but markedly lower beta cell apoptosis, higher beta:alpha cell ratio, greater beta cell area, and enhanced beta cell function.

Conclusions/interpretation Beta cell Fas upregulation by endogenously produced and exogenously applied hIAPP aggregates promotes caspase- 8 activation, resulting in beta cell apoptosis. The prevention of amyloid-induced caspase- 8 activation enhances beta cell survival and function in islets.

Keywords Amylin · Amyloid · Beta cell apoptosis . Caspase- $8 \cdot$ Islet amyloid polypeptide $\cdot$ Islet transplantation . Type 2 diabetes
Abbreviations
DISC Death-inducing signalling complex
FasL Fas ligand
FLIP FLICE inhibitory protein
hIAPP Human islet amyloid polypeptide
PCNA Proliferating cell nuclear antigen
rIAPP Rat islet amyloid polypeptide 


\section{Introduction}

Reduced beta cell mass resulting from increased beta cell apoptosis is a key defect in type 2 diabetes [1, 2]. Islet amyloid formation in patients with type 2 diabetes contributes to progressive beta cell death [3-5]. Unlike in type 2 diabetes, amyloid forms rapidly in cultured [6-8] and transplanted human islets $[9,10]$, and this is associated with beta cell dysfunction and death in vitro [6-8], and with islet graft failure leading to recurrence of hyperglycaemia in animal models of type 1 diabetes [10-12]. Moreover, amyloid deposition associated with reduced beta cell mass has been reported in islet grafts in patients with type 1 diabetes $[13,14]$. Thus islet amyloid, in addition to its role in the pathogenesis of type 2 diabetes, also contributes to islet graft failure in patients with type 1 diabetes.

Islet amyloid polypeptide (amylin), the major component of islet amyloid, is a neuroendocrine hormone that is co-localised and co-secreted with insulin from beta cells in response to beta cell secretagogues [15]. Three major factors contribute to human islet amyloid polypeptide (hIAPP) aggregation in type 2 diabetes: (1) presence of an amyloidogenic sequence in the hIAPP molecule [4]; (2) elevated beta cell production and secretion of hIAPP due to increased insulin demand $[16,17]$; and (3) impaired prohIAPP processing and/or trafficking due to beta cell dysfunction [17-19]. Impaired clearance of secreted hIAPP because of disrupted blood vessels in isolated islets may also potentiate amyloid formation. Islet amyloid is typically found extracellular, adjacent to beta cells [6-8, 13, 20, 21], but intracellular hIAPP aggregates also form in humans and transgenic rodent models [9, 13, 18, 21]. Small hIAPP aggregates appear to be the major mediators of beta cell death [3, 4, 22].

In vitro studies have suggested various mechanisms for amyloid-induced beta cell death, including: the formation of non-selective ion-channel-like structures [23]; interaction of (pro)hIAPP with components of beta cell membranes (e.g. heparan sulphate proteoglycans) [24]; inducing endoplasmic reticulum stress [25] and oxidative stress [26]; and disruption of the endoplasmic reticulum-associated degradation (ERAD)/ubiquitin/proteasome system [27] and autophagy/ lysosomal pathway [28]. Although several mechanisms, at least in vitro, are involved in hIAPP-induced beta cell apoptosis, some of these may share the same apoptotic signalling pathways.

Fas-mediated apoptosis has been implicated in beta cell death in type 2 diabetes [29, 30]. This pathway is initiated by interaction between the cell death receptor Fas (CD95/APO-1) and the Fas ligand (FasL/CD95L), which recruits caspase-8 (FLICE) to the death-inducing signalling complex (DISC) through interaction with the Fas-associated death domain adaptor protein. Cleaved (active) caspase-8 in turn activates downstream caspases, mainly caspase-3 [31]. Moreover, caspase- 8 can indirectly activate caspase- 9 , the key enzyme in the cytochrome $c$ (mitochondrial) apoptotic pathway, by its cleavage of $\mathrm{BH} 3$ interacting domain, which in turn evokes release of cytochrome $c$ from mitochondria [32]. The major endogenous regulator of Fas-mediated apoptosis is the cellular FLICE inhibitory protein (FLIP), which prevents cleavage of procaspase- 8 and subsequent apoptotic signals by its recruitment and cleavage in the DISC instead of procaspase-8 [31].

Islet beta cells constitutively express FasL but do not normally express Fas at detectable levels [7, 29]. However, exposure to metabolic stress such as elevated glucose [29], fatty acids [33], leptin [34] or cytokines (e.g. IL-1 $\beta$ ) [30, 35] induces beta cell Fas upregulation. We recently showed that amyloid formation in human and $\mathrm{h} I A P P$ transgenic mouse islets induces Fas upregulation in beta cells [7]. In this study, we used primary beta cells and human islets to examine whether amyloid-induced Fas upregulation in islet beta cells can promote activation of caspase- 8 , the key enzyme in the Fas-mediated apoptotic pathway. We also generated a mouse model with beta cell specific hIAPP expression and Casp 8 deletion, to test whether blockade of caspase- 8 can protect beta cells from the hIAPP aggregates formed in islets.

\section{Methods}

Human islet isolation and culture Human islets isolated from cadaveric pancreatic donors (36-54 years old) were provided by the Ike Barber Human Islet Transplant Laboratory (Vancouver, BC, Canada) in accordance with approved procedures and guidelines of the Clinical Research Ethics Board of the University of British Columbia. Hand-picked human islets (purity $>90 \%$, dithizone staining) were cultured in CMRL (Mediatech, Herndon, VA, USA) supplemented with $11.1 \mathrm{mmol} / \mathrm{l}$ glucose, $10 \%$ (vol./vol.) FBS, $50 \mathrm{U} / \mathrm{ml}$ penicillin, $50 \mu \mathrm{g} / \mathrm{ml}$ streptomycin and $50 \mu \mathrm{g} / \mathrm{ml}$ gentamicin. Islets were cultured in a humidified $5 \% \mathrm{CO}_{2} / 95 \%$ air incubator $\left(37^{\circ} \mathrm{C}\right.$, 7 days) and the medium was replaced every 2 days.

Animal models Transgenic hemizygous C57BL/6 mice with beta cell $\mathrm{h} I A P P$ expression $\left(\mathrm{h} I A P P^{+/-}\right.$) were kindly provided by S. Kahn (University of Washington, Seattle, WA, USA) and maintained by cross-breeding with $\mathrm{DBA} / 2 \mathrm{~J}$ mice

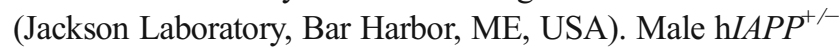
mice on a high-fat diet form islet amyloid and develop amyloid-associated diabetes in about 1 year [20], whereas isolated islets from $\mathrm{h} I A P P^{+/}$mice form amyloid within days during culture with elevated glucose $[7,19,36]$. Mice with beta cell-specific Casp 8 deletion (RIPcre ${ }^{+} \operatorname{Casp} 8^{\mathrm{fl} / \mathrm{fl}}$ ) were generated from $\operatorname{Casp} 8^{\mathrm{fl} / \mathrm{fl}}$ mice [37] using the Cre/loxP recombinase system [38] and maintained by inter-breeding RIP $c r e^{+} \operatorname{Casp} 8^{\mathrm{fl} /+}$ mice. Homozygous mice have agedependent (8-12 months) defects in beta cell mass in the presence of enhanced insulin secretion [38]. 
To generate mice with beta cell-specific $\mathrm{h} I A P P$ expression and Casp 8 deletion, $\mathrm{h} I A P P^{+/-}$and RIPcre $\operatorname{Casp}^{\mathrm{fl} / \mathrm{fl}}$ mice were cross-bred to produce $\mathrm{h} I A P P^{+/-} / \mathrm{RIP} \mathrm{Cre}^{+} \operatorname{Casp} 8^{\mathrm{fl} /+}$ mice, which then were inter-bred to generate $\mathrm{h} I A P P^{+} / \mathrm{RIP} \mathrm{Cr}^{+} \operatorname{Casp} 8^{\mathrm{fl} / \mathrm{fl}}$ and $\mathrm{h} I A P P^{+} / \mathrm{RIP} \mathrm{Cr}^{+} \mathrm{Casp}^{+/+}$mice. The presence of the $\mathrm{h} I A P P$ transgene [39], insulin-cre transgene [40] and disrupted caspase- 8 gene [37] was determined. The first generation of these offspring (10-28 weeks) was used for studies. Animals were fed mouse chow containing 9\% (wt/wt) fat (Purina 5021; LabDiet, Richmond, IN, USA). Animals were cared for in accordance with the Guidelines and Principles of Laboratory Animal Care, and the standard procedures established by the Canadian Council on Animal Care and the University of British Columbia's Animal Policy and Welfare Committee.

Mouse islet isolation Mice were anaesthetised with tribromoethanol $(0.25 \mathrm{mg} / \mathrm{g}$ body weight, i.p. $)$ and killed by cervical dislocation. Ice-cold collagenase $(1,000 \mathrm{U} / \mathrm{ml}$, type XI; Sigma-Aldrich, Oakville, ON, Canada) in $2 \mathrm{ml}$ calcium-free Hanks' buffer was injected via the common bile duct. Pancreases were removed and incubated for 14 min with additional $2 \mathrm{ml}$ collagenase (1,000 U/ml in Hanks' buffer) in a water bath at $37^{\circ} \mathrm{C}$, followed by gentle shaking for $2 \mathrm{~min}$. Digestion was stopped by adding ice-cold Hanks' buffer containing
$1 \mathrm{mmol} / \mathrm{C} \mathrm{CaCl}_{2}$. Digested tissues were rinsed, centrifuged $\left(250 \mathrm{~g}, 30 \mathrm{~s}, 4^{\circ} \mathrm{C}\right)$ and resuspended in the same solution, then filtered through a $70 \mu \mathrm{m}$ mesh cell strainer (BD Biosciences, Oakville, ON, Canada) into Ham's-F10 (Invitrogen, Burlington, ON, Canada). To allow recovery, hand-picked islets (purity $>95 \%$ ) were cultured overnight in Ham's-F10 supplemented with $10 \mathrm{mmol} / 1$ glucose, $0.5 \%$ (wt/vol.) BSA and antibiotics as detailed for human islets, and then cultured for 7 days in Ham's-F10 with 16.7 mmol/l glucose.

Islet dissociation, culture and treatments Human or mouse islets were dissociated as described [41] and cultured in poly-Llysine-coated 8-well chamber slides in CMRL (human) or Ham's-F10 (mouse) with 5.5 and $10 \mathrm{mmol} / 1$ glucose, respectively. Lyophilised hIAPP and rat islet amyloid polypeptide (rIAPP) aliquots were prepared from synthetic peptides (1-37 aa; Bachem, Torrance, CA, USA) as before [41], dissolved fresh in culture medium and added to islet cells at a final concentration of $10 \mu \mathrm{mol} / \mathrm{l}$. The amyloid inhibitor Congo red (Sigma; dissolved in dimethyl sulfoxide), the caspase-8 inhibitor (z-LETDFMK; Bachem) or the Fas antagonist (Kp7-6; EMD Chemicals, Gibbstown, NJ, USA) were prepared in culture medium at final concentrations of $25 \mu \mathrm{mol} / 1,100 \mu \mathrm{mol} / \mathrm{l}$ and $10 \mathrm{mmol} / \mathrm{l}$, respectively, and added to cells $1 \mathrm{~h}$ before hIAPP treatment.
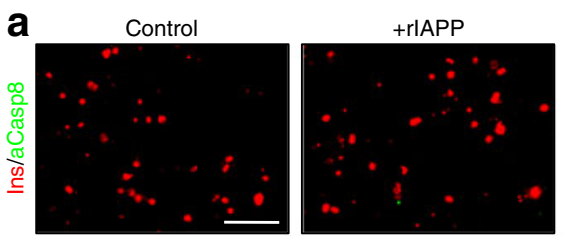

b
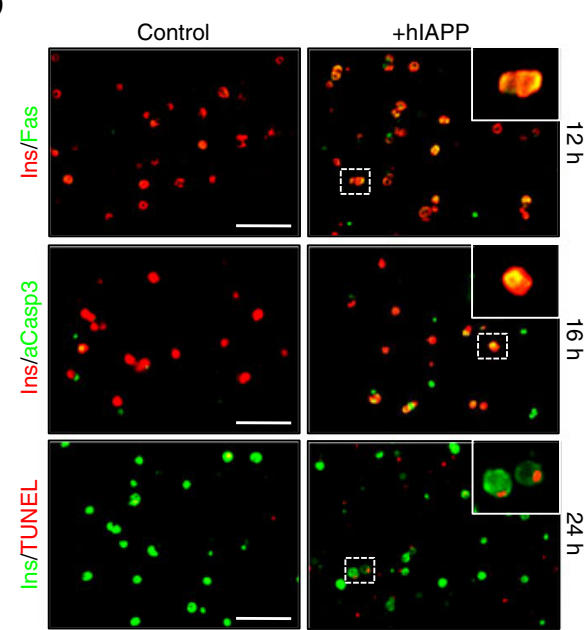

+ hIAPP
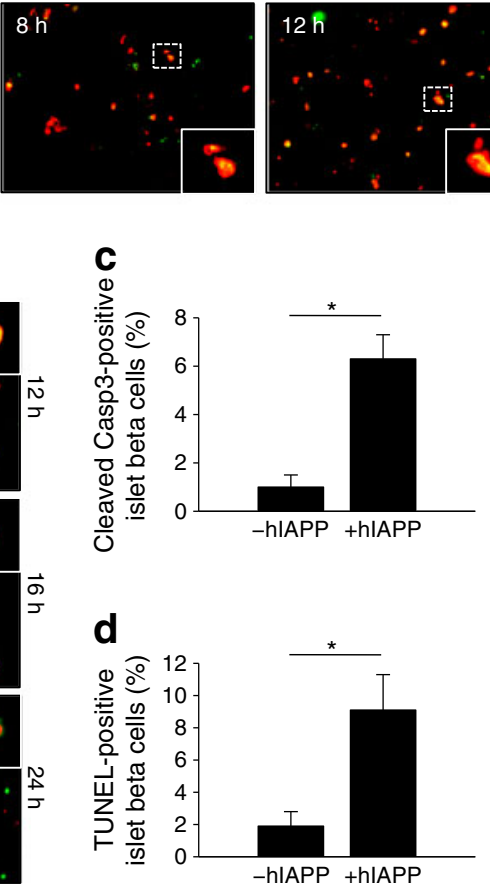

Fig. 1 Exposure to exogenous hIAPP induces caspase-8 activation and apoptosis in human islet beta cells, which is associated with Fas upregulation. (a) Islet cells were immunolabelled for insulin and active caspase-8 (aCasp8) following 8 or $12 \mathrm{~h}$ of treatment with hIAPP or rIAPP. (b) Immunolabelling for insulin and Fas, insulin and active caspase-3 (aCasp3), or insulin and TUNEL as indicated after 12, 16 or $24 \mathrm{~h}$ of
hIAPP treatment, respectively. Scale bar $=100 \mu \mathrm{m}$; inserts: (a) $\times 2.6$; (b) $\times 3.5$. (c) The proportion of beta cells positive for active caspase- 3 and (d) TUNEL in hIAPP-treated and non-treated cells. Quantifications represent a minimum of ten microscopic fields each containing 100 to 150 cells. Results are expressed as means \pm SEM of four independent studies performed in triplicate; ${ }^{*} p<0.05$ by Student's $t$ test 
Immunolabelling of cells and islets Islet cells were fixed in $4 \%$ paraformaldehyde (wt/vol.) and permeabilised with Triton $\mathrm{X}-100$. Paraffin-embedded islet sections $(4 \mu \mathrm{m})$ were dewaxed, rehydrated and blocked in $2 \%$ normal goat or donkey serum (Vector Laboratories, Burlingame, CA, USA). Cells or islet sections (following antigen retrieval with citrate buffer) were incubated overnight at $4{ }^{\circ} \mathrm{C}$ with guinea pig antiinsulin (1:1,000; Dako, Carpinteria, CA, USA) and each of the following: rabbit anti-glucagon (1:750; Dako), cleaved (active) caspase- 8 or -3 (1:100; Cell Signaling, Pickering, ON, Canada), precursor caspase-8 (1:50; Santa Cruz, Santa Cruz, CA, USA), Fas (1:50; Santa Cruz), oligomer (A11) (1:400; Invitrogen), IL-1 $\beta$ (1:100; Santa Cruz) or proliferating cell nuclear antigen (PCNA) (1:250; Cell Signaling). They were then washed with PBS, incubated for $1 \mathrm{~h}$ at room temperature with Texas red-conjugated anti-guinea pig
Fig. 2 Blockade of hIAPPmediated caspase- 8 activation markedly reduces beta cell apoptosis induced by aggregation of exogenously applied hIAPP.

Human islet cells were treated for 8,12 or $24 \mathrm{~h}$ with hIAPP alone or with each of the following: the amyloid inhibitor Congo red (CR), a caspase-8 inhibitor (Casp8 inh) or a Fas antagonist (Kp7-6). (a) Immunolabelling for insulin (red), active caspase- 8 (aCasp8; green) and DAPI (blue). Scale bar $=10 \mu \mathrm{m}$. (b) The proportion of beta cells positive for active caspase-8 and (c) TUNEL. (d) Immunolabelling for insulin and active caspase- 8 , with (e) the proportion of TUNELpositive beta cells in $\mathrm{RIPcre}^{+} \operatorname{Casp}^{\mathrm{fl}^{\mathrm{t} / \mathrm{fl}} \mathrm{l}}$ and wild-type (RIPcre $^{+} \mathrm{Casp}^{+/+}$) mouse islet cells treated with hIAPP for 8 or $24 \mathrm{~h}$, respectively. Scale bar $=$ $50 \mu \mathrm{m}$. Quantifications represent a minimum of ten microscopic fields each containing 100 to 150 islet cells. Results are expressed as means \pm SEM of three independent studies performed in triplicate; ${ }^{*} p<0.05$ by one-way ANOVA a
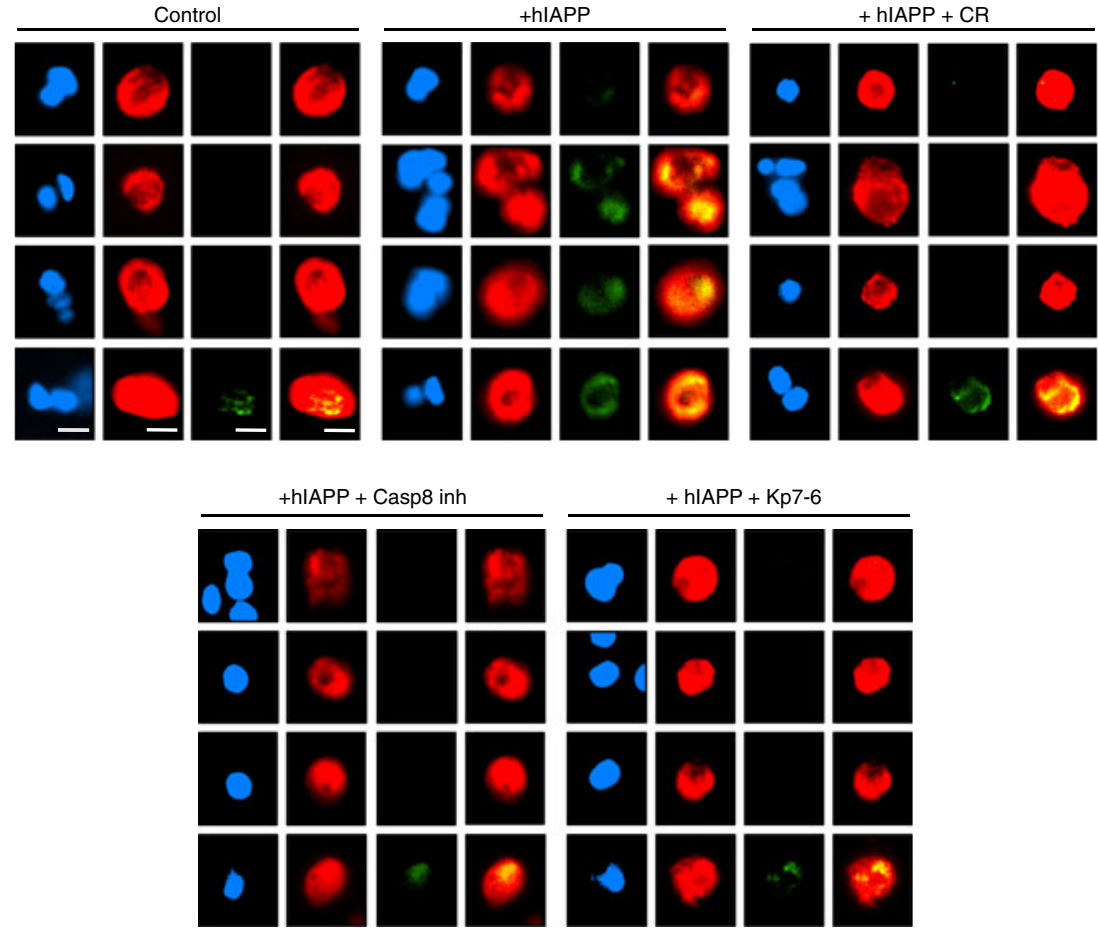

b

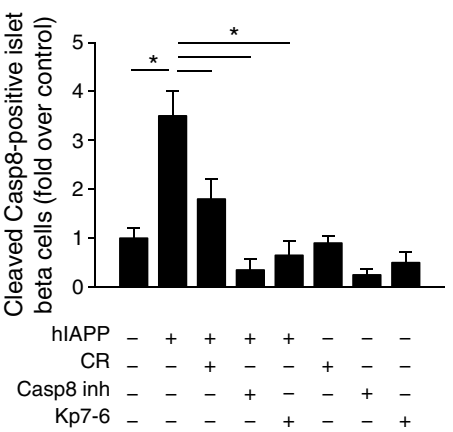

$c$

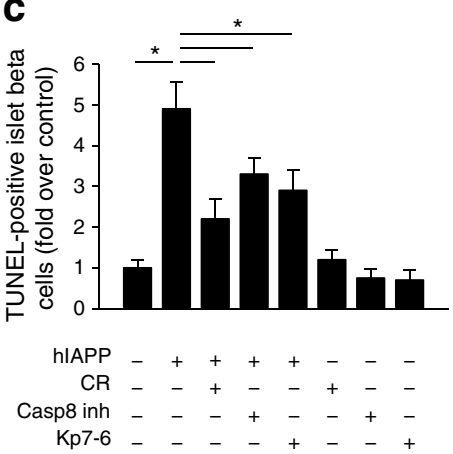

d

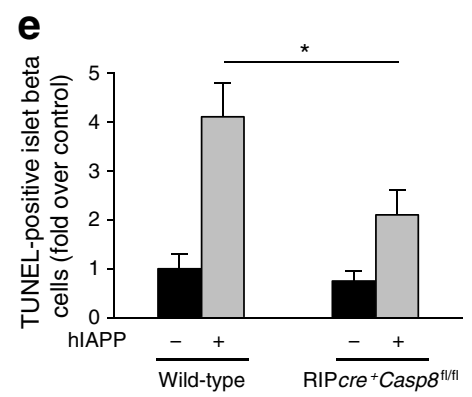


(Jackson Laboratories, West Grove, PA, USA) and Alexa 488conjugated anti-rabbit or anti-mouse (Molecular Probes, Eugene, OR, USA), and counterstained with the nuclear dye DAPI (blue; Vector Laboratories) for quantification studies or with 7-aminoactinomycin D (red; Molecular Probes). For insulin and A11 staining, Alexa 488-conjugated anti-guinea pig (Molecular Probes) and Texas red-conjugated anti-rabbit (Jackson) were used as secondary antibodies, respectively. For TUNEL staining, after immunolabelling for insulin, islet sections (or cells) were incubated $\left(30 \mathrm{~min}, 37^{\circ} \mathrm{C}\right)$ with TUNEL reaction mixture (1:20; Roche Diagnostics, Laval, QC, Canada) and for amyloid staining with $0.5 \%$ (wt/vol.) thioflavin $\mathrm{S}$ solution (5 $\mathrm{min}$, room temperature) (Sigma).

Islet insulin and hIAPP content and release Mouse islets (25 per condition) were pre-incubated $\left(1 \mathrm{~h}, 37^{\circ} \mathrm{C}\right)$ in $\mathrm{KRB}$ buffer containing $10 \mathrm{mmol} / 1 \mathrm{HEPES}$ (pH 7.4), 0.25\% BSA (wt/vol.) and $1.67 \mathrm{mmol} / 1$ glucose, followed by $1 \mathrm{~h}$ incubation in KRB containing $1.67 \mathrm{mmol} / 1$ glucose (basal insulin release) and another hour in KRB containing $16.7 \mathrm{mmol} / \mathrm{l}$ glucose (stimulated insulin release). Islets were lysed in $100 \mu \mathrm{l}$ of $1 \mathrm{~mol} / 1 \mathrm{acetic} \mathrm{acid} / 0.1 \% \mathrm{BSA}\left(10 \mathrm{~min}, 100^{\circ} \mathrm{C}\right)$. Insulin levels were measured by a mouse-specific insulin ELISA kit (Alpco Diagnostics, Salem, NH, USA). Islet hIAPP content and release were assessed by a human amylin (total) ELISA kit (EZHAT-51K; EMD Millipore, Billerica, MA, USA). All values were normalised to islet protein levels (Pierce/ Thermo Scientific, Rockford, IL, USA).

\section{Results}

Exposure to exogenous hIAPP induces caspase-8 activation in human islet beta cells, which is associated with Fas upregulation and precedes caspase-3 activation and apoptosis Human islet cells were cultured in normal glucose with or without synthetic hIAPP or non-fibrillogenic rIAPP at different time points (4-24 h). Non-treated and rIAPP-treated islet cells had very low numbers of beta cells positive for active caspase- 8 (Fig. 1a, Electronic supplementary material [ESM] Fig. 1a).
Fig. 3 The formation of biosynthetic hIAPP aggregates in human islets during culture induces caspase- 8 activation and beta cell apoptosis, which is associated with Fas upregulation. (a) Human islets at days 0 and 7 of culture were immunolabelled as indicated for: insulin, active caspase-8 (aCasp8) and thioflavin $\mathrm{S}$ (Thio S), or inserts: insulin (green) and A11 for smaller hIAPP aggregates (red); insulin and Fas; insulin and TUNEL; and insulin and glucagon. Scale bar= $50 \mu \mathrm{m}$; inserts: $\times 2(\mathrm{~A} 11: \times 3)$. The proportion of (b) thioflavin $\mathrm{S}$ (amyloid)-positive islets to the total number of islets, (c) amyloid area to total islet area, (d) oligomer (A11)-positive islets to the total number of islets, (e) TUNEL-positive beta cells and (f) beta cell area to total islet area. Results are expressed as means \pm SEM of six independent studies; $n=25-30$ islets per condition in each study; ${ }^{*} p<0.05$ by Student's $t$ test a
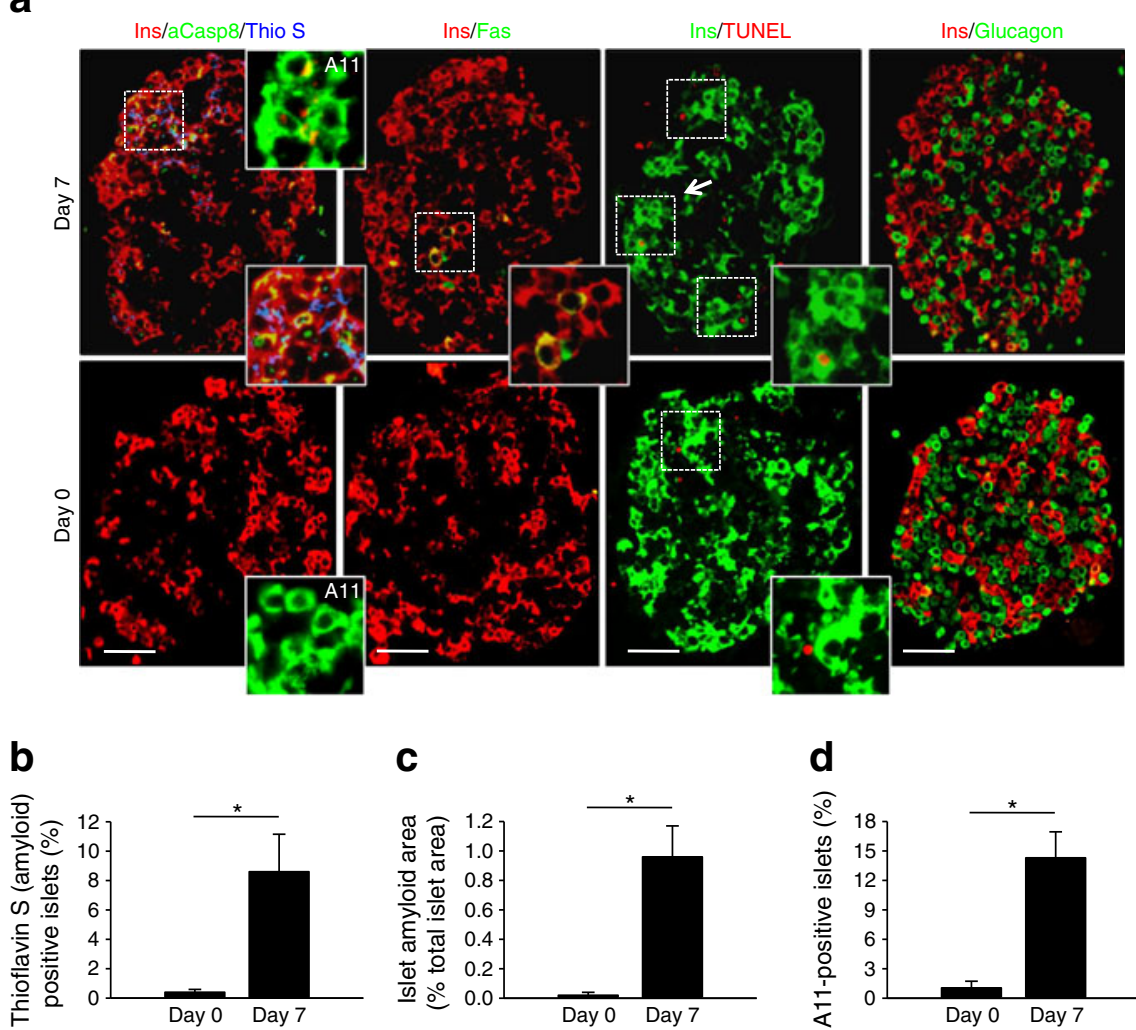

C

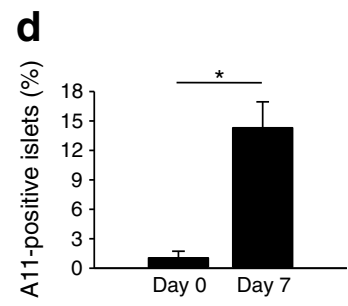

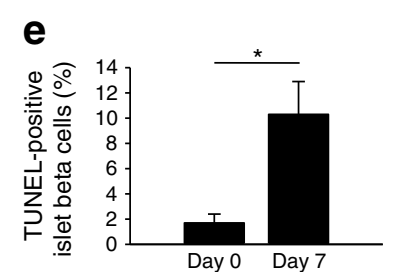

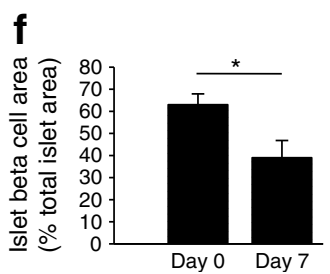


Treatment with hIAPP induced caspase- 8 activation in islet beta cells in a time-dependent manner. The maximum number of beta cells positive for active caspase- 8 was detectable by immunolabelling between 8 and $12 \mathrm{~h}$ after exposure to hIAPP (Fig. 1a). The time point of caspase- 8 activation (8$12 \mathrm{~h}$ ) correlated with that of Fas upregulation (8-12 h), and preceded caspase-3 activation ( $16 \mathrm{~h}$ ) and beta cell apoptosis $(24 \mathrm{~h})$ in hIAPP-treated islet beta cells (Fig. 1b-d, ESM Fig. 1b).

Blocking hIAPP-mediated caspase-8 activation by amyloid, caspase-8 or Fas inhibitors markedly reduces the beta cell apoptosis induced by the aggregation of exogenously applied hIAPP To identify the mechanisms underlying amyloidinduced caspase- 8 activation, we tested the effects of the amyloid inhibitor Congo red, the Fas antagonist and the caspase-8 inhibitor on hIAPP-treated human islet beta cells. The amyloid-binding dye Congo red significantly reduced the number of active caspase- 8 and apoptotic beta cells in hIAPPtreated cells (Fig. 2a-c). Similarly, blockade of Fas (induced by hIAPP) with a Fas antagonist and inhibition of caspase- 8 both markedly lowered the number of active caspase-8positive and apoptotic beta cells in hIAPP-treated islet cells (Fig. 2a-c). Basal death in untreated islet beta cells was comparable with that in cells treated with Congo red alone, but was slightly lower in those treated with the Fas antagonist or caspase-8 inhibitor alone (Fig. 2c). Finally, hIAPP-induced beta cell apoptosis was markedly lower in islet cells from RIPcre ${ }^{+}$asp $8^{\mathrm{fl} / \mathrm{fl}}$ mice lacking caspase- 8 than in wild-type mice that expressed caspase-8 (Fig. 2d, e).

Amyloid formation in human islets during culture induces caspase-8 activation and beta cell death, which is associated with Fas upregulation We examined whether the formation of biosynthetic hIAPP aggregates in human islets during culture can induce caspase- 8 activation in beta cells. Isolated human islets from six donors were cultured for 7 days in elevated glucose to potentiate amyloid formation. Thioflavin $\mathrm{S}$ (amyloid)-positive islets were not detectable in freshly isolated islets from five of six donors, but small amyloid-positive areas were detectable in about $1 \%$ of islets from one donor (Fig. 3a-c). Islet culture resulted in progressive amyloid formation in all human islet preparations. Similarly, oligomer (A11)-positive islets were detectable in cultured islets from all donors (Fig. 3a, d). Importantly, amyloid formation in cultured human islets was associated with caspase-8 activation in beta cells. Furthermore, thioflavin S- or oligomer (A11)positive areas in islets closely correlated with active caspase-
Fig. 4 Beta cell-specific deletion of Casp 8 in h $I A P P$-expressing mouse islets. (a) $\mathrm{h} I A P P$ transgene, disrupted Casp 8 and insulin-cre transgene were detected by PCR performed on tail sample DNA from 3-week-old mice. Results for wild-type littermates with or without Casp 8 deletion and that do not express $\mathrm{h} I A P P$ are shown for comparison. (b) Pancreatic sections from 8-week-old $\mathrm{h} I A P P^{+} / \mathrm{RIP} \mathrm{Cre}^{+} \operatorname{Casp}^{\mathrm{fl} / \mathrm{fl}}$ and $\mathrm{h} I A P P^{+} / \mathrm{RIP} \mathrm{Cr}^{+} \mathrm{Casp}^{+/ 4}$ mice immunolabelled for insulin and full-length caspase-8 (Casp8). The white dashed line outlines the islet in the pancreatic section. (c) Islet sections from each genotype immunolabelled for insulin with thioflavin $\mathrm{S}$ (Thio $\mathrm{S}$ ) and nuclear staining. Scale bar $=50 \mu \mathrm{m}$; inserts: $\times 1.7$ a

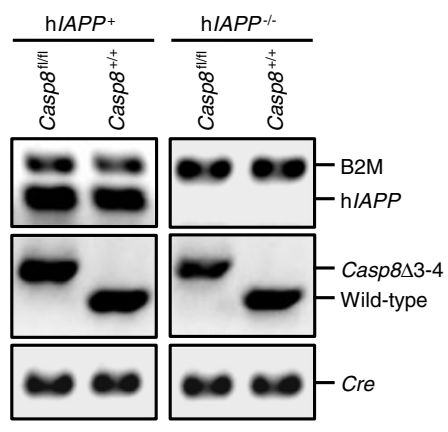

C

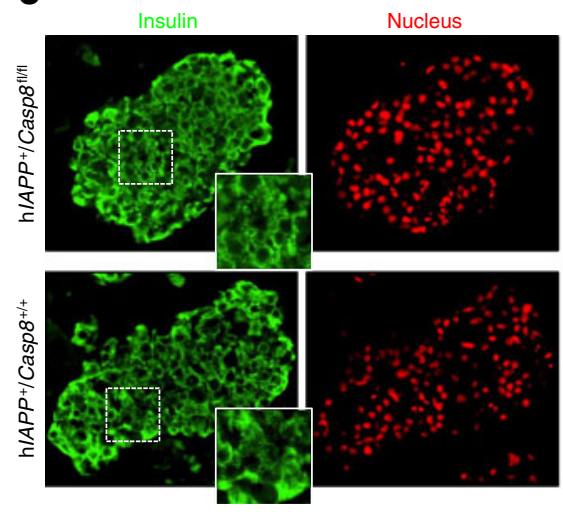

b
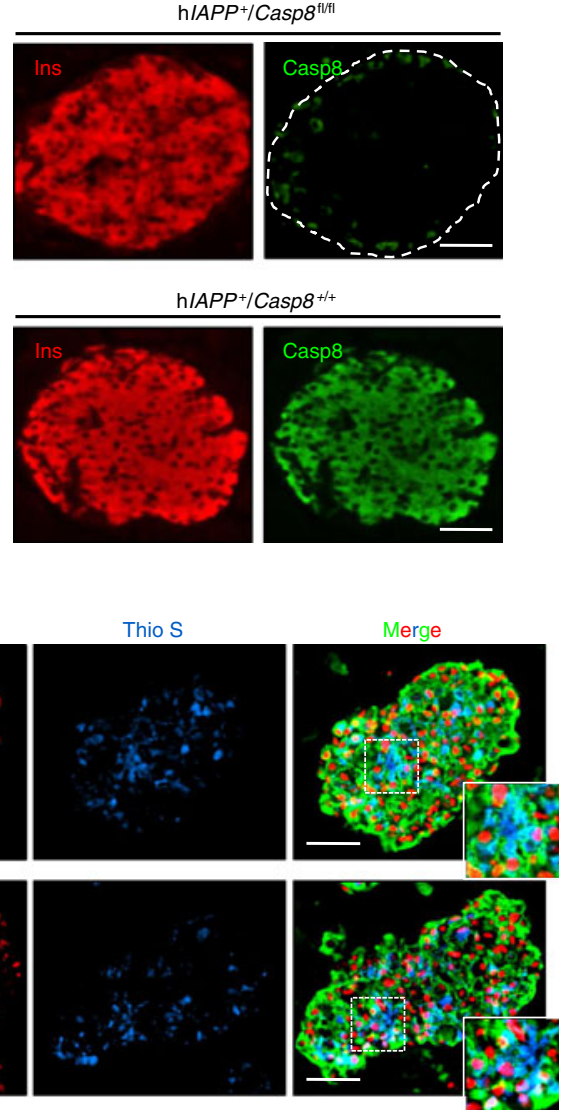
8-positive beta cell areas, both of which were associated with increased beta cell apoptosis (Fig. 3a, e) and reduced islet beta cell area (Fig. 3a, f).

The deletion of Casp8 in hIAPP-expressing mouse islet beta cells markedly reduces apoptosis induced by the aggregation of biosynthetic hIAPP during culture We generated a mouse model with beta cell-specific $\mathrm{h} I A P P$ expression and Casp 8 deletion (Fig. 4), to test whether blockade of caspase- 8 activation can protect beta cells from amyloid toxicity in an ex vivo model of human islet amyloid formation. During 7 days of culture, hIAPP-expressing mouse islets formed amyloid, which was detectable by insulin/thioflavin $\mathrm{S}$ and insulin/oligomer (A11) immunolabelling (Figs 4c, 5a). Cultured islets from $\mathrm{h} I A P P$-expressing mice with or without Casp 8 deletion had comparable levels of amyloid formation, hIAPP content and release (Figs 4c, 5c-g).

Similarly to human islets, the aggregation of biosynthetic hIAPP in transgenic mouse islets during culture induced activation of caspase-8 (Fig. 5a, b). A few active caspase-8positive beta cells were present in cultured islets from wild- type mice expressing caspase-8, but such cells were not detectable in wild-type or $\mathrm{h} I A P P$-expressing islets with beta cell Casp8 deletion (Fig. 5a). Also, a small number of active caspase-8-positive non-beta cells were present in all genotypes. Amyloid formation and amyloid-induced Fas upregulation were associated with elevated islet IL-1 $\beta$ immunoreactivity in cultured $\mathrm{h} I A P P$-expressing mouse islets with and without Casp 8 deletion (Fig. 6a, b). There was no detectable difference between FLIP levels in islet lysates from $\mathrm{h} I A P P$-expressing and wild-type mice (Fig. 6c). Despite similar islet IL-1 $\beta$ and beta cell Fas levels, hIAPP-expressing mouse islets lacking caspase- 8 had significantly lower rates of beta cell apoptosis during culture than islets expressing hIAPP and caspase-8 (Fig. 7a, b), resulting in higher beta:alpha cell ratios and islet beta cell areas in those islets (Fig. 7d, e). Finally, the beta cell proliferation rate was not significantly different in the four genotypes (Fig. 7c).

Cultured hIAPP-expressing mouse islets with Casp8 deletion have enhanced beta cell function compared with those expressing Casp8 Increased beta cell apoptosis in cultured islets from
Fig. 5 Amyloid formation and amyloid-induced caspase- 8 activation in $\mathrm{h} / A P P$-expressing mouse islets with or without beta cell-specific Casp 8 deletion. (a) Islets from wild-type and $\mathrm{h} I A P P$ expressing mice with or without beta cell caspase- 8 deletion were immunolabelled following 7 days culture as indicated for insulin and active caspase-8 (aCasp8); insulin and thioflavin S (Thio S); and insulin and A11 for smaller hIAPP aggregates. Scale bar= $50 \mu \mathrm{m}$; inserts: $\times 1.5($ A $11: \times 3)$.

The proportion of $(\mathbf{b})$ active caspase-8-positive beta cells (fold over wild-type), (c) thioflavin $\mathrm{S}$ (amyloid)-positive islets to the total number of islets, (d) amyloid area to total islet area and (e) oligomer (A11)-positive islets to the total number of islets. (f) Islet hIAPP release and (g) content were assessed in cultured islets from $\mathrm{h} I A P P$-expressing mice with or without Casp 8 deletion (wildtype taken as $100 \%$ ).

Quantifications represent 17-25

islets per animal from each genotype (six to nine mice per group). Results are expressed as means \pm SEM; ${ }^{*} p<0.05$ by

Student's $t$ test

a

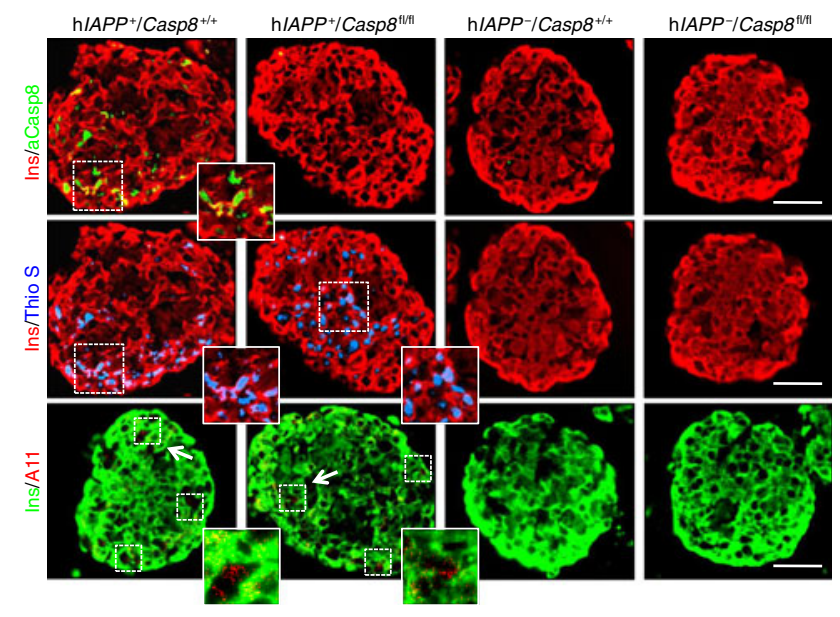

b
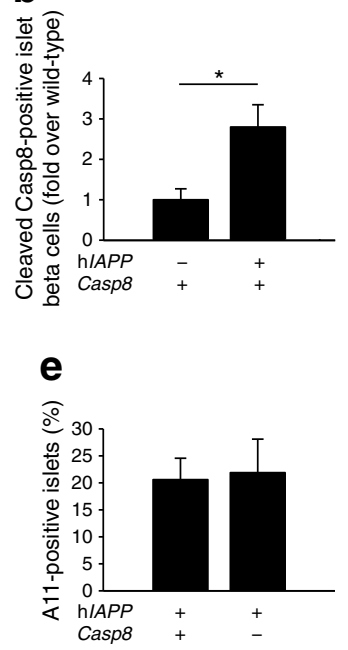

C

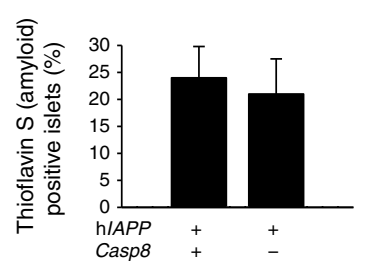

f

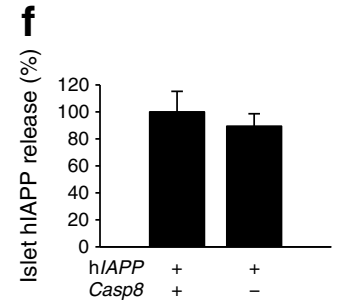

d
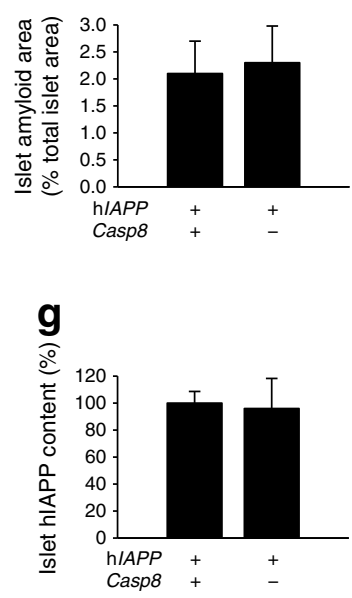
a

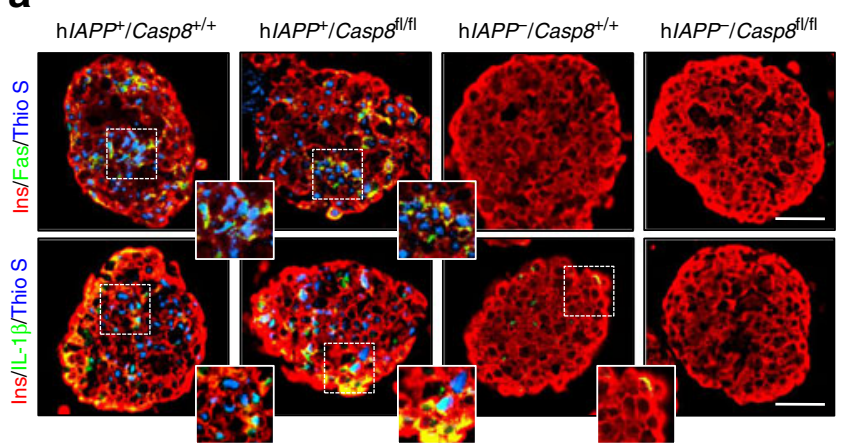

b

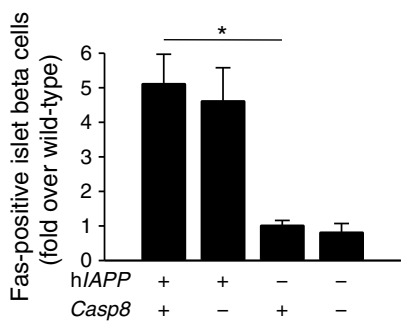

C

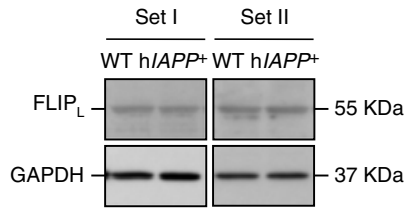

Fig. 6 Fas and IL-1 $\beta$ immunoreactivity, and FLIP protein levels in $\mathrm{h} I A P P$-expressing mouse islets with or without beta cell-specific Casp 8 deletion. (a) Paraffin-embedded sections of 7-day cultured islets from wild-type and $\mathrm{h} L A P P$-expressing mice with or without Casp 8 deletion were immunolabelled as indicated for insulin, Fas and thioflavin $\mathrm{S}$ (Thio S), or insulin, IL-1 $\beta$ and thioflavin S. Scale bar $=50 \mu \mathrm{m}$; inserts: $\times 1.5$. (b) The proportion of Fas-positive islet beta cells (fold over wild-type: $\mathrm{h} J A P P^{-1}$, Casp $\left.8^{+/ /}\right)$. (c) FLIP protein levels in lysates $(15 \mu \mathrm{g})$ from 7-day cultured wild-type and $\mathrm{h} I A P P$-expressing mouse islets (12-14 weeks) using antiFLIP antibody (1:500; Santa Cruz). Quantifications represent 20-25 islets per animal from each genotype (five to six mice per group). Results are expressed as means $\pm \mathrm{SEM} ;{ }^{*} p<0.05$ by one-way ANOVA. FLIP $\mathrm{L}_{\mathrm{L}}$, long form FLIP; GAPDH, glyceraldehyde-3-phosphate dehydrogenase

$\mathrm{h} I A P P$-expressing mice was associated with reduced insulin response to elevated glucose (stimulation index) and reduced insulin content compared with wild-type littermates (Fig. 8). The stimulation index was 32\% higher in cultured islets from $\mathrm{h} I A P P$-expressing mice lacking caspase- 8 than in islets expressing hIAPP and caspase-8, a finding that correlated with the higher $(36 \%)$ insulin content in those islets (Fig. 8). Cultured islets from mice with Casp 8 deletion and without hIAPP expression had a greater (15\%) insulin response to elevated glucose and higher (20\%) insulin content than their wild-type littermates. However, this increase was not as profound as the difference observed between $\mathrm{h} I A P P$-expressing mice lacking or expressing caspase- 8 , suggesting that the deletion of Casp 8 improves the beta cell dysfunction caused by amyloid formation in $\mathrm{h} J A P P$-expressing mouse islets during culture.

\section{Discussion}

We recently showed that hIAPP aggregates induce Fas expression in islet beta cells [7], which do not normally express a

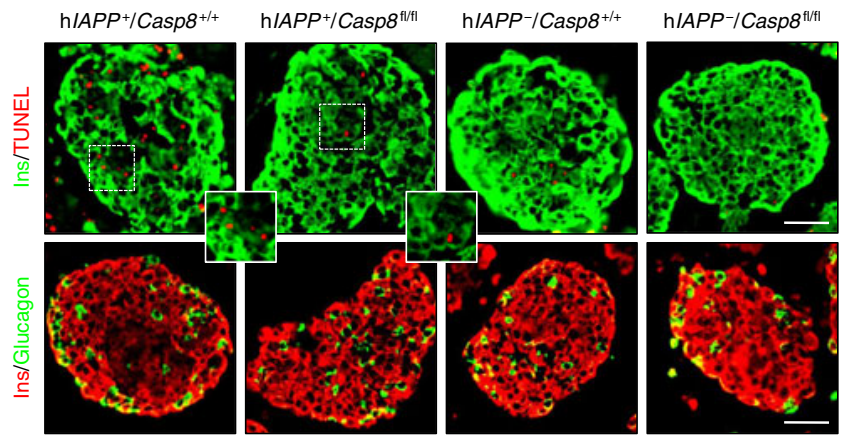

b

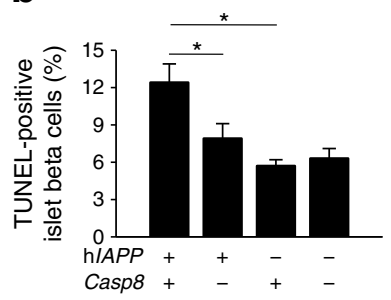

C

d

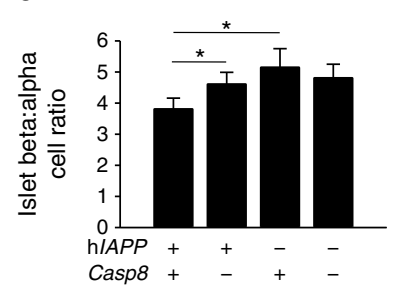

e

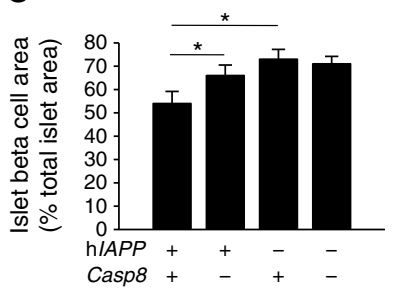

Fig. 7 Beta cell-specific deletion of Casp 8 in $\mathrm{h} I A P P$-expressing mouse islets markedly reduces apoptosis induced by aggregation of biosynthetic hIAPP during culture. (a) Islets from wild-type and $\mathrm{h} I A P P$-expressing mice with or without Casp 8 deletion were immunolabelled following 7 days culture as indicated for insulin and TUNEL, or insulin and glucagon. Scale bar $=50 \mu \mathrm{m}$; inserts: $\times 1.5$. (b) The proportion of apoptotic and (c) proliferating islet beta cells, (d) the islet beta:alpha cell ratio and (e) beta cell area per total islet area in each genotype. Quantifications represent $17-25$ islets per animal from each genotype (six to nine mice per group). Results are expressed as means $\pm \mathrm{SEM} ;{ }^{*} p<0.05$ by one-way ANOVA

Fas at detectable levels [7, 29]. In the present study, using human islet beta cells and two ex vivo models of human islet amyloid formation, we provide direct evidence that amyloidinduced Fas upregulation in islet beta cells can promote activation of caspase-8, the key mediator of Fas apoptotic signalling, thereby initiating apoptosis. We also show that the deletion of Casp 8 protects islet beta cells from the cytotoxic effects of biosynthetic hIAPP aggregates formed in islets.

In human islet beta cells (but not alpha cells), aggregates of exogenously applied hIAPP induced activation of caspase- 8 and -3 , resulting in apoptosis, a process that was prevented by amyloid, caspase- 8 or Fas inhibitors. Caspase- 8 activation preceded caspase- 3 activation and apoptosis, and followed Fas upregulation. These findings suggest that Fas upregulation 
a

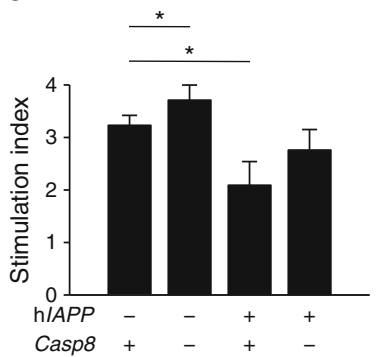

b

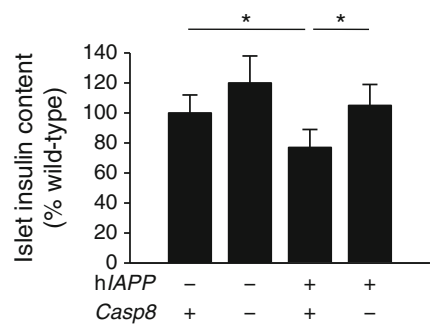

Fig. 8 Cultured h $L A P P$-expressing mouse islets with Casp 8 deletion have enhanced beta cell function compared with those expressing caspase-8. (a) Insulin response to glucose stimulation and (b) insulin content in islets from wild-type and hIAPP-expressing mice with or without Casp 8 deletion following 7 days culture. Glucose-stimulated insulin release (stimulation index) indicates the amount of insulin secreted during $1 \mathrm{~h}$ of incubation at 1.67 (basal) and $16.7 \mathrm{mmol} / 1$ (stimulated) glucose. Insulin content is reported as per cent of the insulin content in wild-type islets, which was set at $100 \%$. Results are expressed as means \pm SEM of five to six animals per genotype; ${ }^{*} p<0.05$ by one-way ANOVA

induced by hIAPP aggregates promotes interaction between Fas and FasL on neighbouring cells (beta cells, other islet or non-islet cells), thereby inducing caspase-8 activation. Consistent with our findings in human islet beta cells, a previous in vitro study showed that synthetic hIAPP induces caspase-8 activation in rodent beta cells [42]. Interestingly, aggregates of amyloid beta peptide were also shown to induce caspase- 8 activation and apoptosis in neural cells, probably via the Fas-mediated apoptotic pathway [43]. Moreover, active caspase-8 and Fas-positive cells have been reported in the brain in Alzheimer's disease [44, 45]. Thus, it seems likely that hIAPP aggregates in type 2 diabetes and amyloid beta aggregates in Alzheimer's disease share the same apoptotic signalling pathway(s).

The formation of biosynthetic hIAPP aggregates in human and $\mathrm{h} I A P P$-expressing mouse islets during culture was associated with caspase- 8 activation in beta cells, leading to increased beta cell apoptosis and reduced beta cell mass. Interestingly, despite comparable levels of amyloid, IL-1 $\beta$ and Fas in cultured $\mathrm{h} I A P P$-expressing mouse islets with or without caspase- 8 expression, islets lacking caspase- 8 had markedly lower beta cell apoptosis, a higher beta:alpha cell ratio and a greater islet beta cell area than islets expressing caspase-8. Moreover, deletion of Casp 8 in $\mathrm{h} L A P P$-expressing mouse islets enhanced beta cell function, suggesting that the inhibition of caspase- 8 can reduce the beta cell toxicity and improve the beta cell dysfunction mediated by biosynthetic hIAPP aggregates.

The majority of islets with amyloid formation were positive for IL- $1 \beta$, Fas and caspase- 8 immunoreactivity, whereas islets with no detectable amyloid formation had very low levels of all three, suggesting that amyloid may induce Fas upregulation and caspase- 8 activation by promoting IL- $1 \beta$ release in islets. In support of this, hIAPP aggregates have been shown

to promote maturation of proIL- $1 \beta$ to IL- $1 \beta$ via activation of the NLR family pyrin domain containing 3 (NLRP3) inflammasome [46, 47]. In addition, we recently showed that the inhibition of amyloid formation reduces islet IL- $1 \beta$ levels and Fas upregulation [7]. The cell source(s) of IL-1 $\beta$ in amyloid-positive islets could be beta cells, non-beta or nonislet cells (e.g. macrophages). Both macrophage-positive and macrophage-negative islet areas have been reported in $\mathrm{h} I A P P$ transgenic mouse islets [46]. It seems therefore that macrophages are the major, but possibly not the only source of amyloid-induced IL-1 $\beta$ production in islets. Taken together, these findings suggest that amyloid formation may contribute to islet inflammation in patients with type 2 diabetes [48].

The balance between caspase- 8 and its cellular regulator FLIP can switch Fas-mediated signalling to apoptosis or proliferation $[49,50]$. This raises the possibility that hIAPP aggregates, like elevated glucose, may reduce beta cell FLIP levels, thereby switching Fas signalling towards apoptosis. Although we did not detect any significant difference between FLIP protein levels in lysates from 7-day islet cultures from $\mathrm{h} I A P P$-expressing and wild-type mice, it is possible that potential effects of hIAPP aggregates on beta cell FLIP levels were masked in our experimental model for the following reasons: (1) elevated glucose (used to potentiate amyloid formation) can increase FLIP levels in wild-type and hIAPPexpressing mouse islets; and (2) FLIP protein levels were measured in lysates from islet cultures that contained amyloid-positive and -negative islets.

In summary, our studies show that beta cell Fas upregulation induced by hIAPP aggregates is probably mediated via release of IL- $1 \beta$ from islets and promotes Fas and FasL interaction, thereby initiating Fas-mediated apoptosis. We also show that deletion of Casp 8 protects islet beta cells from amyloid toxicity, suggesting that caspase- 8 plays a significant role in amyloid-induced beta cell apoptosis.

Acknowledgements Human islets for these studies were provided by the Ike Barber Human Islet Transplant Laboratory (Vancouver, BC, Canada). Human $I A P P$ transgenic mice were kindly provided by S. Kahn (VA Puget Sound Health Care System, University of Washington, Seattle, WA, USA). We gratefully acknowledge the outstanding technical contribution of I. Barta (Department of Pathology and Laboratory Medicine, University of British Columbia, Vancouver, BC, Canada), A. Asadi and T. Webber (Department of Cellular and Physiological Sciences, University of British Columbia, Vancouver, BC, Canada) to the completion of these studies.

Funding This work was supported by grants from the Canadian Institutes of Health Research (CIHR) to LM (MOP-126204) and MW (MOP-81148). Infrastructure support was provided by a grant from the Canadian Foundation for Innovation (LM). YJP is the recipient of a studentship from the CIHR Transplant Research Training Program.

Duality of interest The authors declare that there is no duality of interest associated with this manuscript. 
Contribution statement All authors contributed to the study conception and design, or the analysis and interpretation of data, as well as to the drafting of the article or its critical revision for important intellectual content. All authors gave final approval of the version to be published.

\section{References}

1. Butler AE, Janson J, Bonner-Weir S, Ritzel R, Rizza RA, Butler PC (2003) Beta-cell deficit and increased beta-cell apoptosis in humans with type 2 diabetes. Diabetes 52:102-110

2. Hanley SC, Austin E, Assouline-Thomas B et al (2010) Beta-cell mass dynamics and islet cell plasticity in human type 2 diabetes. Endocrinology 151:1462-1472

3. Haataja L, Gurlo T, Huang CJ, Butler PC (2008) Islet amyloid in type 2 diabetes, and the toxic oligomer hypothesis. Endocr Rev 29:303-316

4. Westermark P, Andersson A, Westermark GT (2011) Islet amyloid polypeptide, islet amyloid, and diabetes mellitus. Physiol Rev 91: 795-826

5. Jurgens CA, Toukatly MN, Fligner CL et al (2011) Beta-cell loss and beta-cell apoptosis in human type 2 diabetes are related to islet amyloid deposition. Am J Pathol 178:2632-2640

6. Marzban L, Tomas A, Becker TC et al (2008) Small interfering RNAmediated suppression of proislet amyloid polypeptide expression inhibits islet amyloid formation and enhances survival of human islets in culture. Diabetes 57:3045-3055

7. Park YJ, Lee S, Kieffer TJ et al (2012) Deletion of Fas protects islet beta cells from cytotoxic effects of human islet amyloid polypeptide. Diabetologia 55:1035-1047

8. Park YJ, Ao Z, Kieffer TJ et al (2013) The glucagon-like peptide-1 receptor agonist exenatide restores impaired pro-islet amyloid polypeptide processing in cultured human islets: implications in type 2 diabetes and islet transplantation. Diabetologia 56:508-519

9. Westermark G, Westermark P, Eizirik DL et al (1999) Differences in amyloid deposition in islets of transgenic mice expressing human islet amyloid polypeptide versus human islets implanted into nude mice. Metabolism 48:448-454

10. Potter KJ, Abedini A, Marek P et al (2010) Islet amyloid deposition limits the viability of human islet grafts but not porcine islet grafts. Proc Natl Acad Sci U S A 107:4305-4310

11. Udayasankar J, Kodama K, Hull RL et al (2009) Amyloid formation results in recurrence of hyperglycaemia following transplantation of human IAPP transgenic mouse islets. Diabetologia 52:145-153

12. Westwell-Roper C, Dai DL, Soukhatcheva G et al (2011) IL-1 blockade attenuates islet amyloid polypeptide-induced proinflammatory cytokine release and pancreatic islet graft dysfunction. J Immunol 187:2755-2765

13. Westermark GT, Westermark P, Berne C, Korsgren O (2008) Widespread amyloid deposition in transplanted human pancreatic islets. N Engl J Med 359:977-979

14. Westermark GT, Davalli AM, Secchi A et al (2012) Further evidence for amyloid deposition in clinical pancreatic islet grafts. Transplantation 93:219-223

15. Kahn SE, D'Alessio DA, Schwartz MW et al (1990) Evidence of cosecretion of islet amyloid polypeptide and insulin by beta-cells. Diabetes 39:634-638

16. Hou X, Ling Z, Quartier E et al (1999) Prolonged exposure of pancreatic beta cells to raised glucose concentrations results in increased cellular content of islet amyloid polypeptide precursors. Diabetologia 42:188-194

17. Zheng X, Ren W, Zhang S et al (2010) Serum levels of proamylin and amylin in normal subjects and patients with impaired glucose regulation and type 2 diabetes mellitus. Acta Diabetol 47:265-270
18. Paulsson JF, Andersson A, Westermark P, Westermark GT (2006) Intracellular amyloid-like deposits contain unprocessed pro-islet amyloid polypeptide (proIAPP) in beta cells of transgenic mice overexpressing the gene for human IAPP and transplanted human islets. Diabetologia 49:1237-1246

19. Marzban L, Rhodes CJ, Steiner DF, Haataja L, Halban PA, Verchere CB (2006) Impaired NH2-terminal processing of human proislet amyloid polypeptide by the prohormone convertase PC2 leads to amyloid formation and cell death. Diabetes 55:2192-2201

20. Verchere CB, D'Alessio DA, Palmiter RD et al (1996) Islet amyloid formation associated with hyperglycemia in transgenic mice with pancreatic beta cell expression of human islet amyloid polypeptide. Proc Natl Acad Sci U S A 93:3492-3496

21. Janson J, Soeller WC, Roche PC et al (1996) Spontaneous diabetes mellitus in transgenic mice expressing human islet amyloid polypeptide. Proc Natl Acad Sci U S A 93:7283-7288

22. Gurlo T, Ryazantsev S, Huang CJ et al (2010) Evidence for proteotoxicity in beta cells in type 2 diabetes: toxic islet amyloid polypeptide oligomers form intracellularly in the secretory pathway. Am J Pathol 176:861-869

23. Demuro A, Mina E, Kayed R, Milton SC, Parker I, Glabe CG (2005) Calcium dysregulation and membrane disruption as a ubiquitous neurotoxic mechanism of soluble amyloid oligomers. J Biol Chem 280:17294-17300

24. Park K, Verchere CB (2001) Identification of a heparin binding domain in the $\mathrm{N}$-terminal cleavage site of pro-islet amyloid polypeptide. Implications for islet amyloid formation. J Biol Chem 276: 16611-16616

25. Huang CJ, Lin CY, Haataja L et al (2007) High expression rates of human islet amyloid polypeptide induce endoplasmic reticulum stress mediated beta-cell apoptosis, a characteristic of humans with type 2 but not type 1 diabetes. Diabetes 56: 2016-2027

26. Zraika S, Hull RL, Udayasankar J et al (2009) Oxidative stress is induced by islet amyloid formation and time-dependently mediates amyloid-induced beta cell apoptosis. Diabetologia 52:626-635

27. Costes S, Huang CJ, Gurlo T et al (2011) Beta-cell dysfunctional ERAD/ubiquitin/proteasome system in type 2 diabetes mediated by islet amyloid polypeptide-induced UCH-L1 deficiency. Diabetes 60: 227-238

28. Rivera JF, Gurlo T, Daval M et al (2011) Human-IAPP disrupts the autophagy/lysosomal pathway in pancreatic beta-cells: protective role of p62-positive cytoplasmic inclusions. Cell Death Differ 18: $415-426$

29. Maedler K, Spinas GA, Lehmann R et al (2001) Glucose induces beta-cell apoptosis via upregulation of the Fas receptor in human islets. Diabetes 50:1683-1690

30. Maedler K, Sergeev P, Ris F et al (2002) Glucose-induced beta cell production of IL-1 beta contributes to glucotoxicity in human pancreatic islets. J Clin Invest 110:851-860

31. Lavrik IN, Krammer PH (2012) Regulation of CD95/Fas signaling at the DISC. Cell Death Differ 19:36-41

32. Kaufmann T, Strasser A, Jost PJ (2012) Fas death receptor signalling: roles of Bid and XIAP. Cell Death Differ 19:42-50

33. Boni-Schnetzler M, Boller S, Debray S et al (2009) Free fatty acids induce a proinflammatory response in islets via the abundantly expressed interleukin-1 receptor I. Endocrinology 150:5218-5229

34. Maedler K, Sergeev P, Ehses JA et al (2004) Leptin modulates beta cell expression of IL-1 receptor antagonist and release of IL-1beta in human islets. Proc Natl Acad Sci U S A 101:8138-8143

35. Donath MY, Shoelson SE (2011) Type 2 diabetes as an inflammatory disease. Nat Rev Immunol 11:98-107

36. Zraika S, Hull RL, Udayasankar J et al (2007) Glucose- and time-dependence of islet amyloid formation in vitro. Biochem Biophys Res Commun 354:234-239 
37. Salmena L, Lemmers B, Hakem A et al (2003) Essential role for caspase 8 in $\mathrm{T}$ cell homeostasis and $\mathrm{T}$ cell-mediated immunity. Genes Dev 17:883-895

38. Liadis N, Salmena L, Kwan E et al (2007) Distinct in vivo roles of caspase- 8 in beta-cells in physiological and diabetes models. Diabetes 56:2302-2311

39. Andrikopoulos S, Verchere CB, Terauchi Y, Kadowaki T, Kahn SE (2000) Beta-cell glucokinase deficiency and hyperglycemia are associated with reduced islet amyloid deposition in a mouse model of type 2 diabetes. Diabetes 49:2056-2062

40. Postic C, Shiota M, Niswender KD et al (1999) Dual roles for glucokinase in glucose homeostasis as determined by liver and pancreatic beta cell-specific gene knock-outs using Cre recombinase. J Biol Chem 274:305-315

41. Law E, Lu S, Kieffer TJ et al (2010) Differences between amyloid toxicity in alpha and beta cells in human and mouse islets and the role of caspase-3. Diabetologia 53:1415-1427

42. Zhang S, Liu H, Yu H, Cooper GJ (2008) Fas-associated death receptor signaling evoked by human amylin in islet beta-cells. Diabetes 57:348-356

43. Wei W, Norton DD, Wang X, Kusiak JW (2002) Abeta 17-42 in Alzheimer's disease activates JNK and caspase-8 leading to neuronal apoptosis. Brain J Neurol 125:2036-2043
44. Rohn TT, Head E, Nesse WH, Cotman CW, Cribbs DH (2001) Activation of caspase- 8 in the Alzheimer's disease brain. Neurobiol Dis 8:1006-1016

45. Yew DT, Ping Li W, Liu WK (2004) Fas and activated caspase 8 in normal, Alzheimer and multiple infarct brains. Neurosci Lett 367: $113-117$

46. Masters SL, Dunne A, Subramanian SL et al (2010) Activation of the NLRP3 inflammasome by islet amyloid polypeptide provides a mechanism for enhanced IL-1beta in type 2 diabetes. Nat Immunol 11:897-904

47. Westwell-Roper C, Dunne A, Kim ML, Verchere CB, Masters SL (2013) Activating the NLRP3 inflammasome using the amyloidogenic peptide IAPP. Methods Mol Biol 1040:9-18

48. Donath MY, Dalmas E, Sauter NS, Boni-Schnetzler M (2013) Inflammation in obesity and diabetes: islet dysfunction and therapeutic opportunity. Cell Metab 17:860-872

49. Maedler K, Fontana A, Ris F et al (2002) FLIP switches Fas-mediated glucose signaling in human pancreatic beta cells from apoptosis to cell replication. Proc Natl Acad Sci U S A 99:8236-8241

50. Maedler K, Schumann DM, Sauter N et al (2006) Low concentration of interleukin-1 beta induces FLICE-inhibitory protein-mediated beta-cell proliferation in human pancreatic islets. Diabetes 55: $2713-2722$ 